\title{
STATUS GIZI STUNTING TERHADAP TINGKAT PERKEMBANGAN ANAK USIA BALITA
}

\author{
Yena Wineini Migang \\ Poltekkes Kemenkes Palangka Raya \\ Yenawineini.migang @yahoo.co.id
}

\begin{abstract}
The problem of stunting is the main program that gets priority intervention because it is associated with the risk of morbidity and mortality, one of which is stunted brain development.. Data from the Indonesian Ministry of Health, Directorate General of Public Health, Directorate of Nutrition, Central Kalimantan in 2015 the percentage of stunting aged 0-59 months was (38.4\%), 2016 (34.1\%) and 2017 (39.0\%) in 2018 (34\%) ). The 2020-2024 RPJM targets 19\% and Central Kalimantan targets the next 4 years of $20 \%$ of the incidence of stunting and was issued by Governor Regulation No.13 of 2019 concerning actions to accelerate the prevention of stunting in 2019-2023. The research objective was to see the difference in the proportion of children under five development in the stunting nutritional status group of children children under five with normal nutrition. The research was carried out in Sebangau Subdistrict, Pulang Pisau Regency in 2019. The number of respondents was 30 groups of children children under five with stunting and 30 normal children children under five, with a case control study, purposive sampling technique, and Chi Square statistical test and Fisher Exact Test and binomial alternatives. There is a significant difference in the proportion of underfives' nutritional status with under-five development $0.000<0.05$ where the development of late children under fives in the stunting nutritional status group (43.3\%) is not the same as the normal nutritional status (3.3\%) with OR (22.176) where the group of children children under five with nutritional status had a risk of 22 times the risk of developmental delays compared to the group of children children under five with normal nutritional status.
\end{abstract}

Keywords $\quad$ : Stunting, Children Under Five, Development

\begin{abstract}
ABSTRAK
Balita pendek (stunting) menjadi program utama mendapat prioritas intervensi karena berhubungan dengan risiko terjadinya kesakitan dan kematian, salah satunya perkembangan otak terhambat. Balita akan mengalami keterlambatan perkembangan, mempengaruhi pada masa usia produktif. Data Kemenkes RI Dirjen Kesmas, Direktorat Gizi, Kalimantan Tengah tahun 2015 persentase stunting usia 0-59 bulan sebanyak $(38,4 \%)$ tahun $2016(34,1 \%)$ tahun $2017(39,0 \%)$, tahun 2018 (34\%) dan tahun 2019 (32\%) hal ini masih jauh dari target RPJM tahun 2020-2024 (19\%). Provinsi Kalteng target 4 tahun kedepan (20\%) kejadian stunting. Tujuan penelitian ini menguji beda proporsi perkembangan balita pada kelompok balita status gizi stunting dengan kelompok balita status gizi normal, serta beberapa variabel lainnya yang berhubungan dengan perkembangan balita. Penelitian di Kecamatan Sebangau Kabupaten Pulang Pisau pada tahun 2019. Jumlah responden ada 30 kelompok anak balita stunting dan 30 anak balita yang normal, desain studi kasus kontrol, tehnik pengambilan sampel purposive sampling, uji statistik Chi Square dan alternatif Fisher Exact Test dan binomial. Ada perbedaan signifikan proporsi status gizi balita dengan perkembangan balita $0,000<0,05$. Proporsi perkembangan balita terlambat pada kelompok balita status gizi stunting $(43,3 \%)$ tidak sama dengan kelompok balita status gizi normal $(3,3 \%)$ dengan OR $(22,176)$ dimana kelompok balita status gizi stunting beresiko 22 kali keterlambatan perkembangan dibandingkan kelompok balita status gizi normal.
\end{abstract}

Kata Kunci : Stunting, Balita, Perkembangan

\section{PENDAHULUAN}

Stunting menjadi permasalahan karena berhubungan dengan meningkatnya risiko terjadinya kesakitan dan kematian, perkembangan otak terhambat (Organization, 2013); (Permatasari \& 
Sumarmi, 2018). Stunting merupakan kurang gizi kronis yang disebabkan oleh asupan gizi yang kurang dalam waktu cukup lama akibat pemberian makanan yang tidak sesuai dengan kebutuhan gizi. Stunting terjadi mulai janin masih dalam kandungan dan baru nampak saat anak berusia dua tahun (Rosadi, Rahayuh, Yulidasari, Putri, \& Rahman, 2016). Stunting menyebabkan kemampuan kognitif para penderita juga berkurang, sehingga mengakibatkan kerugian ekonomi jangka panjang bagi Indonesia. Indonesia menduduki peringkat kelima dunia untuk jumlah anak dengan kondisi stunting (Tim Nasional Pencegahan Penanggulangan Kemiskinan (TNP2K), 2018).

Beberapa studi menunjukkan risiko yang diakibatkan stunting yaitu penurunan prestasi akademik, meningkatkan risiko obesitas lebih rentan terhadap penyakit tidak menular dan peningkatan risiko penyakit degeneratif. Anak-anak yang terhambat pertumbuhannya sebelum berusia 2 (dua) tahun memiliki hasil yang lebih buruk dalam emosi dan perilakunya pada masa remaja akhir (Rindu Dwi Malateki Solihin, Faisal Anwar, 2013). Stunting merupakan prediktor buruknya kualitas sumber daya manusia yang selanjutnya akan berpengaruh pada pengembangan potensi bangsa (Tim Nasional Pencegahan Penanggulangan Kemiskinan (TNP2K), 2013). Stunting merupakan bentuk kegagalan pertumbuhan (growth faltering) akibat akumulasi ketidakcukupan nutrisi yang berlangsung lama mulai dari kehamilan sampai usia 24 bulan (Wiyogowati, 2012).

Banyak faktor yang menyebabkan tingginya kejadian stunting pada balita. Penyebab langsung adalah kurangnya asupan makanan dan adanya penyakit infeksi (Tangerang \& Arlius, 2017). Faktor lainnya adalah pengetahuan ibu yang kurang, pola asuh yang salah, sanitasi dan hygiene yang buruk dan rendahnya pelayanan kesehatan, selain itu masyarakat belum menyadari anak pendek merupakan suatu masalah, karena anak pendek di masyarakat terlihat sebagai anak-anak dengan aktivitas yang normal, tidak seperti anak kurus yang harus segera ditanggulangi (K. E. Kusuma, 2013); (Migang, Rarome, Heriteluna, \& Dawam, 2020). Gizi ibu waktu hamil, masyarakat belum menyadari pentingnya gizi selama kehamilan berkontribusi terhadap keadaan gizi bayi yang akan dilahirkannya kelak Menyingkapi tingginya prevalensi stunting ini, yang terkonsentrasi di beberapa dunia negaranegara termiskin, Organisasi Kesehatan Dunia (WHO) telah mengusulkan target global penurunan kejadian stunting pada anak dibawah usia lima tahun sebesar $40 \%$ pada tahun 2025 .

Data Kemenkes RI Dirjen Kesmas, Direktorat Gizi, Kalimantan Tengah tahun 2015 persentase stunting usia 0-59 bulan sebanyak $(38,4 \%)$ tahun $2016(34,1 \%)$ tahun 2017 (39,0\%), tahun 2018 (34\%) dan tahun 2019 (32\%) hal ini masih jauh dari target RPJM tahun 2020-2024 (19\%). Provinsi Kalteng target 4 tahun kedepan $20 \%$ kejadian stunting. Kalteng target 4 tahun kedepan (20\%) kejadian stunting dan dikeluarkan Pergub no 13 tahun 2019 tentang aksi percepatan penanggulangan stunting tahun 2019-2023. Bersadarkan data Puskesmas Sebangau tahun 2018 bulan Oktober, dari 203 orang balita yang dilakukan pemeriksaan status gizi TB/U, 66 orang terdeteksi pendek dan sangat pendek (stunting). Ini berarti 32,5\% anak usia balita di Kecamatan Sebangau mengalami stunting. Sedangkan menurut hasil Pantauan Status Gizi (PSG) nasional kabupaten Pulang Pisau menempati posisi sepuluh besar kabupaten yang tinggi persentase kejadian stunting di Provinsi Kalimantan Tengah mencapai $(35,4 \%)$, sedangkan persentase Bumil resiko kurang energi kalori (KEK) sebanyak (13.8\%) dan WUS (Wanita Usia Subur) resiko KEK mencapai (11.0\%) (Kemenkes R.I., 2017). Menurut hasil penimbangan serentak yang dilakukan di Kecamatan Sebangau Kuala Kab. Pulang Pisau pada bulan Oktober 2018, didapatkan status gizi anak balita 0-59 bulan berdasarkan $\mathrm{TB} / \mathrm{U}$ mencapai $6,9 \%$ sangat pendek, $25,6 \%$ pendek, dan $66,5 \%$ normal 
(Database Puskesmas Sebangau Kuala, 2018). Salah satu akibat dari status gizi stunting akan menurunkan tingkat perkembangan pada anak, terutama saat masa usia produktif. Permasalahan gizi adalah permasalahan dalam siklus kehidupan, dari masa kehamilan. Balita yang mengalami stunting beresiko akan mengalami gangguan perkembangan (Wiyogowati, 2012). Tujuan penelitian ini ingin menguji beda proporsi perkembangan balita pada kelompok balita status gizi stunting dengan kelompok balita gizi normal, dan melihat peluang resiko keterlambatan perkembangan antara kelompok balita status gizi stunting dengan balita status gizi normal

\section{METODE}

Desain penelitian studi kasus kontrol. Tujuan penelitian ini ingin menguji beda proporsi perkembangan balita pada kelompok balita status gizi stunting dengan kelompok balita gizi normal, dan melihat peluang resiko keterlambatan perkembangan antara kelompok balita status gizi stunting dengan balita status gizi normal.

Subyek penelitian adalah anak usia balita usia 12 bulan sampai 36 bulan.. Jumlah responden ada 30 kelompok anak balita stunting dan 30 anak balita yang normal, dengan tehnik pengambilan sampel purposive sampling, dimana kriteria inklusinya anak balita yang diasuh satu rumah dengan ibu kandung, dan kriteria ekslusi bila mengalami kelainan kongenital. Pelaksanaan penelitian di Kecamatan Sebangau Kabupaten Pulang Pisau tahun 2019. Uji statistik chi square dengan alternatif fisher exact test dan binomial. Menggunakan instrumen penelitian aplikasi WHO Anthro untuk mengukur nilai Z-score status gizi balita dan pengukuran perkembangan menggunakan instrumen DDST Denver II

\section{HASIL}

Setelah dilakukan analisa univariat dan bivariat dengan menggunakan uji chi square, berikut hasil penelitian pada enam variabel penelitian. Variabel independen adalah status gizi balita, penyakit infeksi, pemberian ASI ekslusif, pendidikan ibu dan pekerjaan ibu. Variabel dependen adalah perkembangan balita.

\section{Analisa Univariat}

Berdasarkan hasil distribusi univariat variabel pada Tabel 1, terlihat bahwa kelompok status gizi balita yang stunting dan normal, masing-masing 30 subyek penelitian.

Tabel 1 Distribusi Variabel Penelitian

\begin{tabular}{lll}
\hline Variabel & $\mathrm{f}$ & $\%$ \\
\hline Status Gizi Balita & & \\
$\quad$ Stunting & 30 & 50 \\
$\quad$ Normal & 30 & 50 \\
Perkembangan Balita & & \\
$\quad$ Terlambat & 14 & 23,3 \\
$\quad$ Normal & 46 & 76,7 \\
Penyakit Infeksi >3 & & \\
bulan terakhir & & \\
$\quad$ Sakit & 7 & 11,7 \\
$\quad$ Tidak sakit & 53 & 88,3 \\
Pemberian ASI ekslusif & & \\
$\quad$ Tidak ASI ekslusif & 12 & 20 \\
$\quad$ ASI ekslusif & 48 & 80 \\
Pendidikan Ibu & & \\
$\quad$ Tidak sekolah & 1 & 1,7 \\
$\quad$ SD & 20 & 33,3 \\
$\quad$ SMP & 18 & 30,0 \\
$\quad$ SMA & 20 & 33,3 \\
$\quad$ Perguruan Tinggi & 1 & 1,7 \\
Pekerjaan Ibu & & \\
$\quad$ Tidak bekerja & 52 & 86,7 \\
Bekerja & 8 & 13,3 \\
& & \\
\hline
\end{tabular}

Perkembangan normal $(76,7 \%)$, dan subyek penelitian yang tidak sakit $<3$ bulan terakhir $(88,3 \%),(80 \%)$ riwayat balita diberikan ASI ekslusif, pendidikan ibu persentase tertinggi pada tingkat SD dan SMA masing-masing sama $(33,3 \%)$ dan status pekerjaan ibu, tidak bekerja( $86,7 \%)$.

\section{Analisa Bivariat}


Berikut tabel 2 adalah hasil uji statistik dengan menggunakan uji chi square dan alternatif fisher exact test, binomial untuk beberapa hasil yang tidak memenuhi syarat untuk menggunakan chi square. Seluruh variabel menggunakan skala data nominal, data dikotomi untuk menyesuaikan tabel $2 \times 2$, kecuali variabel pendidikan ibu.

Tabel 2. Hubungan Status Gizi Balita, Penyakit Infeksi, Pemberian ASI Ekslusif, Pendidikan Ibu dan Pekerjaan Ibu dengan Perkembangan Balita

\begin{tabular}{|c|c|c|c|c|c|c|}
\hline \multirow{3}{*}{ Variabel } & \multicolumn{4}{|c|}{ Perkembangan Balita } & \multirow{3}{*}{$\rho$} & \multirow{3}{*}{ OR } \\
\hline & \multicolumn{2}{|c|}{ Terlambat } & \multicolumn{2}{|c|}{ Normal } & & \\
\hline & $\mathrm{f}$ & $\%$ & f & $\%$ & & \\
\hline \multicolumn{7}{|l|}{ Status Gizi Balita } \\
\hline Stunting & 13 & 43,3 & 17 & 56,7 & \multirow[t]{2}{*}{0,000} & 22,176 \\
\hline Normal & 1 & 3,3 & 29 & 96,7 & & $(2,661-184,798)$ \\
\hline \multicolumn{7}{|l|}{$\begin{array}{l}\text { Penyakit Infeksi >3 } \\
\text { bulan terakhir }\end{array}$} \\
\hline Sakit & 4 & 57,1 & 3 & 42,9 & \multirow[t]{2}{*}{$0,045^{*}$} & 5,733 \\
\hline Tidak sakit & 10 & 18,9 & 43 & 81,1 & & $(1.104-29,780)$ \\
\hline \multicolumn{7}{|c|}{ Pemberian ASI ekslusif } \\
\hline Tidak ASI ekslusif & 3 & 25,0 & 9 & 75,0 & \multirow[t]{2}{*}{1.000} & 1,721 \\
\hline ASI ekslusif & 11 & 22,9 & 37 & 77,1 & & $(0,258-4,875)$ \\
\hline \multicolumn{7}{|l|}{ Pendidikan Ibu } \\
\hline Tidak sekolah & 0 & 0 & 1 & 100 & \multirow[t]{5}{*}{$0,915 * *$} & \multirow[t]{5}{*}{-} \\
\hline $\mathrm{SD}$ & 5 & 25 & 15 & 75 & & \\
\hline SMP & 5 & 27,8 & 13 & 72,2 & & \\
\hline SMA & 4 & 20 & 16 & 80 & & \\
\hline Perguruan Tinggi & 0 & 0 & 1 & 100 & & \\
\hline \multicolumn{7}{|l|}{ Pekerjaan Ibu } \\
\hline Tidak bekerja & 10 & 19,2 & 42 & 80,8 & \multirow[t]{2}{*}{0,077} & 0,238 \\
\hline Bekerja & 4 & 50 & 4 & 50 & & $(0,051-1,120)$ \\
\hline
\end{tabular}

Ada perbedaan signifikan proporsi status gizi balita dengan perkembangan balita $0,000<0,05$. Proporsi perkembangan balita terlambat pada kelompok balita status gizi stunting $(43,3 \%)$ tidak sama dengan kelompok balita status gizi normal $(3,3 \%)$ dengan OR $(22,176)$ dimana kelompok balita status gizi stunting beresiko 22 kali keterlambatan perkembangan dibandingkan kelompok balita status gizi normal.

\section{PEMBAHASAN}

\section{Status Gizi dengan Perkembangan Balita}

Penelitian ini mengambil subyek penelitian balita 12 bulan sampai dengan 36 bulan, artinya balita tersebut sudah melewati masa ASI ekslusif dan sudah makan dengan gizi sesuai kebutuhan (Hanum \& Khosman, 2012). Pada usia ini sudah dapat terlihat apakah terjadi stunting atau tidak, dan mudah untuk dideteksi keterlambatan perkembangan. (Probosiwi, Huriyati, \& Ismail, 2017).

Instrumen yang digunakan untuk mengukur status gizi adalah software $\mathrm{WHO}$ Anthro, akan di hitung nilai Z-score masingmasing subyek penelitian yang kemudian akan ditentukan status gizi berdasarkan tinggi badan dibandingkan usia (TB/U). Pengukuran perkembangan menggunakan instrumen Denver Developmental Screening Test (DDST), yang akan diukur adalah komponen kognitif, personal sosial, motorik halus, bahasa, dan motorik kasar.

Pada penelitian ini didapat hasil ada perbedaan signifikan proporsi status gizi balita dengan perkembangan balita $0,000<0,05$. Proporsi perkembangan balita terlambat pada kelompok balita status gizi stunting $(43,3 \%)$ tidak sama dengan kelompok balita status gizi normal $(3,3 \%)$ 
dengan OR $(22,176)$ dimana kelompok balita status gizi stunting beresiko 22 kali keterlambatan perkembangan dibandingkan kelompok balita status gizi normal.

Hasil penelitian ini sejalan beberapa penelitianlainnya yang mengatakan ada hubungan antara status gizi balita dengan perkembangan balita maka nilai $\rho(0,000)$ dimana nilai $\alpha(0,05$ (Setiawan, Machmud, \& Masrul, 2018) dalam penelitian tersebut menyatakan status gizi merupakan salah satu faktor penyebab stunting. Masa balita merupakan periode penting dalam tumbuh kembang anak karena pertumbuhan dasar yang berlangsung pada masa balita akan mempengaruhi dan menentukan perkembangan anak selanjutnya. Seperti diketahui bahwa tiga tahun (baduta) pertama merupakan periode keemasan (golden period), yaitu terjadi optimalisasi proses tumbuh kembang. Dalam pertumbuhan dan perkembangan anak memerlukan zat gizi agar proses pertumbuhan dan perkembangan berjalan dengan baik(Annisa, Sumiaty, \& Tondong, 2019). Zat-zat gizi yang dikonsumi balita akan berpengaruh pada status gizi balita (Khoeroh, Handayani, \& Indriyanti, 2017).

Status gizi harus diperhatikan sejak janin dalam kandungan karena kondisi Berat badan lahir rendah, yaitu kurang dari 2,5 kilogram dengan panjang badan yang kurang dari $48 \mathrm{~cm}$ beresiko untuk mengalami gangguan nutrisi yang akan mempengaruhi perkembangan otak anak (Ningrum \& Utami, 2014). Ternyata berat lahir rendah berisiko 2,4 kali lipat untuk mengalami keterlambatan perkembangan (KI 95\%: 0,9-0,7; $\mathrm{p}=0,042$ ). Kepadatan hunian berisiko 3,8 kali lipat untuk mengalami keterlambatan perkembangan (KI 95\% :0,8-17,6; p=0,038). Bahwa hubungan sangat lemah antara perkembangan balita dengan faktor risiko berupa pendidikan ibu, pendapatan keluarga (Hartono dkk, 2019).

Umur anak 24-60 bulan merupakan salah satu masa krisis bagi anak balita yang terus terbentuk jaringan otaknya perkembangan balita umur 24-60 bulan dengan nilai hubungan status gizi $\mathrm{p}$ sebesar 0,493. Posisi korelasinya sangat lemah dengan perkembangan balita (R. M. Kusuma, 2019). Beberapa penelitian juga menyatakan ada hubungan antara status gizi dengan perkembangan balita, tetapi status gizi balita ditentukan sejak janin dalam kandungan ibu, seperti berat lahir rendah, dan kondisi ini dapat pula mempengaruhi perjalanan perkembangan balita nantinya. Pentingnya status gizi janin yang nantinya mempengaruhi berat badan saat lahir dan perkembangan otak, maka perlu diperhatikan dengan intervensi gizi spesifik salah satunya memperhatikan status gizi ibu hamil (Migang et al., 2020).

Perkembangan balita harus diperhatikan, terdapat pengaruh antara perkembangan bahasa terhadap perkembangan kognitif pada anak usia 1-3 tahun. Bayi yang mengalami keterlambatan bahasa awal dapat dinyatakan bahwa ditemukan masalah neurodevelopmental. Keterlambatan bahasa ekspresi dan reseptif oleh para ahli sering dikaitkan dengan kelemahan aspek kognitif secara umum. Keterlambatan terjadi dapat dikarenakan kurangnya stimulasi bahasa dari orang tua atau pendamping balita. Banyak upaya yang dilakukan oleh orangtua agar anaknya dapat melalui masa perkembangan dengan tepat (Rindu Dwi Malateki Solihin, Faisal Anwar, 2013).

\section{Penyakit Infeksi > 3 Bulan Terakhir dengan Perkembangan Balita}

Pada penelitian ini berdasarkan hasil uji statistik ada beda proporsi antara kelompok balita yang mengalami penyakit infeksi $>3$ bulan dengan kelompok balita yang tidak mengalami penyakit infeksi > 3 bulan terhadap keterlambatan perkembangan. Peluang kelompok balita yang mengalami penyakit infeksi > 3 bulan beresiko 6 kali mengalami perkembangan terlambat dibanding kelompok yang tidak mengalami penyakit infeksi $>3$ bulan.

Penyakit infeksi merupakan salah satu faktor penyebab langsung stunting, Kaitan antara penyakit infeksi dengan pemenuhan 
asupan gizi tidak dapat dipisahkan. Adanya penyakit infeksi akan memperburuk keadaan bila terjadi (Nadhiroh, 2010). Penyakit infeksi yang lama, melebihi tiga bulan dapat mengganggu perkembangan karena kondisi sakit dapat melemahkan fungsi organ tubuh untuk melakukan proses pertumbuhna dan perkembangan (Kasim, Malonda, \& Amisi, 2019); (Namangboling, Murti, \& Sulaeman, 2017). Hasil penelitian (Wilar, P.Moonik, \& H Lestari, 2015) memperlihatkan infeksi ibu pada masa prenatal, status gizi, pemberian ASI, perawatan kesehatan, pendapatan orangtua, pendidikan orangtua dan jumlah saudara tidak memiliki hubungan bermakna terhadap keterlambatan perkembangan anak dimana nilai $(\mathrm{p}=0,05)$.

Pemenuhan zat gizi yang sudah sesuai dengan kebutuhan namun penyakit infeksi yang diderita tidak tertangani akan tidak dapat memperbaiki status kesehatan dan status gizi anak balita. Untuk itu penanganan terhadap penyakit infeksi yang diderita sedini mungkin akan membantu perbaikan gizi dengan diiimbangi pemenuhan asupan yang sesuai dengan kebutuhan anak balita. Penyakit infeksi yang sering diderita balita seperti cacingan, Infeksi saluran pernafasan Atas (ISPA), diare dan infeksi lainnya sangat erat hubungannya dengan status mutu pelayanan kesehatan dasar khususnya imunisasi, kualitas lingkungan hidup dan perilaku sehat ((Nations \& Unicef, 2013); (Hanum \& Khosman, 2012)). Ada beberapa penelitian yang meneliti tentang hubungan penyakit infeksi dengan stunting yang menyatakan bahwa diare merupakan salah satu faktor risiko kejadian stunting pada anak usia dibawah 5 tahun(Tim Nasional Percepatan Penanggulangan Kemiskinan, 2017).

\section{Pemberian ASI Ekslusif, Pendidikan Ibu, Pekerjaan Ibu dengan Perkembangan Balita}

Pada penelitian ini variabel pemberian ASI ekslusif, pendidikan ibu dan pekerjaan tidak memiliki beda proporsi yang signifikan terhadap perkembangan terlambat pada balita. Dimana didapat bahwa nilai $\rho>0,05$. Hal ini sejalan dengan beberapa penelitian yang mengatakan bahwa pada usia lebih dari 12 bulan hal yang paling mempengaruhi status gizi adalah pola makan (Destiadi, Susila, \& Sumarmi, 2013). Usia di atas 12 bulan tidak lagi mendapatkan ASI ekslusif lagi, seharusnya sudah mendapatkan makanan padat yang komposisi gizinya sesuai kebutuhan, artinya bila mengalami kekurangan akan beresiko terjadinya gangguan nutrisi. Kuantitas asupan gizi dalam pemberian makan pada balita sangat tergantung pada pola asuh pemberian makan oleh pengasuh(Hanum \& Khosman, 2012).Jadi walaupun balita memiliki riwayat pemberian ASI ekslusif dapat saja balita dalam perkembangannya mendapat keterlambatan.

Pendidikan dan pekerjaan ibu, pada penelitian ini juga tidak memiliki beda proporsi dengan perkembangan balita. Beberapa penelitian mengatakan bahwa stimulasi orangtua saat mengasuh balita sangat mempengaruhi perkembangan, salah satu yang mempengaruhi adalah pengetahuan ibu. Pada Penelitian ini tidk ada mengukur tingkat pengetahuan ibu, sehingga tidak diketahui apakah ada hubungan dengan perkembangan balita. Keterlambatan terjadi dapat dikarenakan kurangnya stimulasi bahasa dari orang tua atau pendamping balita. Banyak upaya yang dilakukan oleh orangtua agar anaknya dapat melalui masa perkembangan dengan tepat. Salah satunya seperti penelitian (Muniroh \& Ni'mah, 2015)

Stimulasi agar anak dapat bersosialisasi dengan baik. Kemampuan balita melakukan sosialisasi dan kemandirian merupakan salah satu poin utama penilaian perkembangan. Kemampuan balita melakukan sosialisasi dipengaruhi oleh pola asuh. Pola asuh ada beberapa macam salah satunya ada non otoritatif. Hal ini sesuai dengan penelitian yang menyatakan pola asuh non otoritatif berhubungan dengan kekurangan kemampuan sosialisasi anak. Perilaku ibu yang hangat berkaitan dengan kemampuan sosialisasi anak dalam 
membina hubungan interpersonal dengan teman sebaya dan lingkungan sosia (RI, 2016). Pola asuh orang tua memiliki pengaruh yang besar pada perilaku anak, namun penelitian ini tidak ada meneliti sampai pada pola asuh orang tua, hanya sebatas pendidikan dan pekerjaan ibu.

\section{KESIMPULAN}

Berdasarkan hasil penelitian dan merujuk pada tujuan penelitian, maka dapat diambil kesimpulan sebagai berikut: Ada perbedaan signifikan proporsi status gizi balita dengan perkembangan balita $0,000<0,05$. Proporsi perkembangan balita terlambat pada kelompok balita status gizi stunting $(43,3 \%)$ tidak sama dengan kelompok balita status gizi normal $(3,3 \%)$ dengan OR $(22,176)$ dimana kelompok balita status gizi stunting beresiko 22 kali keterlambatan perkembangan dibandingkan kelompok balita status gizi normal. Ada beda proporsi perkembangan balita pada kelompok balita penyakit infeksi $>3$ bulan dan yang tidak ada penyakit infeksi $>3$ bulan dengan OR $(5,733)$ dimana kelompok balita menderita penyakit infeksi $>3$ bulan 6 kali beresiko mengalami keterlambatan perkembangan.

Keterlambatan perkembangan pada balita memerlukan waktu yang lama dan lebih kemungkinan berhubungan dengan status gizi ibu saat hamil, artinya sejak dalam kandungan. Perlu pemantauan status gizi ibu hamil secara intensif melalui program intervensi gizi sensitif dan spesifik.

\section{UCAPAN TERIMAKASIH}

Penulis juga mengucapkan terima kasih kepada Dinas Kesehatan Kabupaten Pulang Pisau. Terima kasih kepada Direktur Poltekkes Kemenkes Palangka Raya berserta Wadir I,II, dan III yang telah memfasilitasi pelaksanaan penelitian ini. Terima kasih kepada para subyek penelitian yang telah kooperatif saat proses pengumpulan data.

\section{DAFTAR PUSTAKA}

Annisa, N., Sumiaty, S., \& Tondong, H. I. (2019). Hubungan Inisiasi Menyusu Dini dan ASI Eksklusif dengan Stunting pada Baduta Usia 7-24 Bulan. Jurnal Bidan Cerdas (JBC), 2(2), https://doi.org/10.33860/jbc.v2i2.1 98

Destiadi, A., Susila, T., \& Sumarmi, S. (2013). Frekuensi Kunjungan Posyandu dan Riwayat Kenaikan Berat badan sebagai Faktor Risiko Kejadian Stunting pada Anak Usia 3-5 Tahun. Media Gizi Indonesia, Vol.10 No., hlm.71-75.

Hanum, N. L., \& Khosman, A. (2012). Pola Asuh Makan, Perkembangan Bahasa, dan Kognitif Anak Balita Stunted dan Normal di Kelurahan Sumur Batu, Bantar Gebang Bekasi. Gizi Dan Pangan, 7(2), 81-88.

Hartono Gunardi, Resyana P. Nugraheni, Annisa R. Yulman, S., \& Rini Sekartini, Bernie E. Medise, Angga Wirahmadi, E. M. (2019). Paediatrica Indonesiana, 59(5), 276-283.

Kasim, E., Malonda, N., \& Amisi, M. (2019). Hubungan Antara Riwayat Pemberian Imunisasi dan Penyakit Infeksi dengan Status Gizi pada Anak Usia 24-59 Bulan di Kecamatan Ratahan Kabupaten Minahasa Tenggara. (Relationship Between History of Immunization and Infectious Disease with Nutritional Status i. Jurnal Bios Logos, $\quad 9(1), \quad 34$. https://doi.org/10.35799/jbl.9.1.201 9.23421

Kemenkes R.I. (2017). Buku Saku Pemantuan Status Gizi Tahun 2017. Jakarta: Departemen Kesehatan Republik Indonesia.

Khoeroh, H., Handayani, O. W. K., \& Indriyanti, D. R. (2017). Evaluasi Penatalaksanaan Gizi Balita Stunting Di Wilayah Kerja 
Puskesmas Sirampog. Unnes Journal of Public Health, 6(3), 189. https://doi.org/10.15294/ujph.v6i3. 11723

Kusuma, K. E. (2013). Faktor Risiko Kejadian Stunting pada Anak Usia 2-3 Tahun ( Studi di Kecamatan Semarang Timur ). Universitas Diponegoro.

Kusuma, R. M. (2019). Hubungan Status Gizi Dengan Perkembangan Anak Umur 24-60 Bulan di Kelurahan Bener Kota Yogyakarta. Jurnal Kesehatan Vokasional, 4(3).

Migang, Y. W., Rarome, M. J., Heriteluna, M., \& Dawam, M. (2020). Intervention of Specific Nutrition and Sensitive Nutrition with Nutritional Status of Under TwoYear Infants in Family Planning Village as Efforts to Face the Demographic Bonus. Jurnal Kesehatan Masyarakat, 16(1), 101110.

https://doi.org/10.15294/kemas.v16 i1.23172

Muniroh, L., \& Ni'mah, C. (2015). Hubungan tingkat pendidikan, tingkat pengetahuan dan pola asuh ibu dengan. Media Gizi Indonesia, 10, No 1, 84-90.

Nadhiroh, S. R. (2010). Faktor yang berhubungan dengan kejadian.

Namangboling, A. D., Murti, B., \& Sulaeman, E. S. (2017). Hubungan Riwayat Penyakit Infeksi dan Pemberian ASI Eksklusif dengan Status Gizi Anak Usia 7-12 Bulan di Kecamatan Kelapa Lima Kota Kupang. Sari Pediatri, 19(2), 91. https://doi.org/10.14238/sp19.2.201 7.91-6

Nations, U., \& Unicef, F. (2013). Improving Chils Nutrition The achievable imperative for global progress. New York.

Ningrum, E. W., \& Utami, T. (2014). PERBEDAAN STATUS GIZI STUNTING

DAN PERKEMBANGAN ANTARA
BALITA RIWAYAT BBLR DENGAN BALITA BERAT LAHIR NORMAL The Differences Of Nutritional Status And Development Between Child With History Of Low Birth Weight Infant And Normal Weight Infant, (2).

Organization, W. H. (2013). CHILDHOOD STUNTING: Challenges and opportunities. Geneva.

Permatasari, D. F., \& Sumarmi, S. (2018). Differences of Born Body Length, History of Infectious Diseases, and Development between Stunting and Non-Stunting Toddlers. Jurnal Berkala Epidemiologi, 6(2), 182. https://doi.org/10.20473/jbe.v6i220 18.182-191

Probosiwi, H., Huriyati, E., \& Ismail, D. (2017). Stunting dan perkembangan anak usia 12-60 bulan di Kalasan. Journal of Community Medicine and Public Health, (November), 1141-1146.

RI, K. kesehatan. (2016). Pedoman Pelaksanaan Stimulasi, Deteksi dan Intervensi Dini Tumbuh Kembang anak. Jakarta: Kementerian Kesehatan RI.

Rindu Dwi Malateki Solihin, Faisal Anwar, dan D. S. (2013). Kaitan Antara Status Gizi, Perkembangan Kognitif, dan Perkembangan Motorik Pada Usia Prasekolah (Relationship Between Nutritional Status, Cognitive development, And Motor Development in Preschool Children), 36(1), 62-72.

Rosadi, D., Rahayuh, A., Yulidasari, F., Putri, A. O., \& Rahman, F. (2016). Faktor Risiko Yang Berhubungan Dengan Kejadian Pendek Pada Anak Usia 6-24 Bulan. Jurnal Kesehatan Masyarakat, 11(2), 233. https://doi.org/10.15294/kemas.v11 i 2.4512

Setiawan, E., Machmud, R., \& Masrul, M. (2018). Faktor-Faktor yang Berhubungan dengan Kejadian Stunting pada Anak Usia 24-59 
Bulan di Wilayah Kerja Puskesmas Andalas Kecamatan Padang Timur Kota Padang Tahun 2018. Jurnal Kesehatan Andalas, 7(2), 275. https://doi.org/10.25077/jka.v7.i2.p 275-284.2018

Tangerang, K., \& Arlius, A. (2017). Hubungan Ketahanan Pangan Keluarga Dengan Status Gizi Balita ( Studi Di Desa Palasari Dan Puskesmas Kecamatan Legok , 23(3), 359-375.

Tim Nasional Pencegahan Penanggulangan Kemiskinan (TNP2K), S. W. P. R. (2013). Stunting dan Masa Depan Indonesia, 2010, 2-5.

Tim Nasional Pencegahan Penanggulangan Kemiskinan (TNP2K), S. W. P. R. (2018). Mendorong Konvergensi dan Efektifititas Upaya Percepatan
Penurunan Stunting (Vol. 5).

Tim Nasional Percepatan Penanggulangan

Kemiskinan. (2017). 100

Kabupaten/Kota Prioritas untuk Intervensi Anak Kerdil ( (Vol. 1). Jakarta. Retrieved from www.tnp2k.go.id

Wilar, R., P.Moonik, \& H Lestari, H. (2015). Faktor-faktor yang mempengaruhi keterlambatan perkembangan anak taman kanakkanak 2. Jurnal E-Clinic (ECl), 3(April).

Wiyogowati, C. (2012). Kejadian stunting pada anak berumur dibawah lima tahun tahun (0-59 bulan) di provinsi papua barat tahun 2010 (analisis data riskesdas 2010). Universitas Indonesia. 